\title{
Inter-model agreement on projected shifts in California hydroclimate characteristics critical to water management
}

\author{
Geeta G. Persad, et al. [full author details at the end of the article]
}

Received: 4 March 2020 / Accepted: 25 September 2020 / Published online: 3 October 2020

(C) The Author(s) 2020

\begin{abstract}
Shifts away from the historical hydroclimate in populated regions can have dire consequences for water management. Regions like the state of California-where highly engineered, geographically interconnected, and inflexible water management systems are predicated on particular spatiotemporal patterns of water availability - are particularly vulnerable to hydroclimate shifts. However, much of the analysis of hydroclimate sensitivity to anthropogenic climate change has focused on gross metrics like annual mean precipitation, which is highly uncertain at the regional scale. This perceived uncertainty has deterred adaptation investments and quantitative integration of climate projection data into regional water management. Here, we assess projected future shifts in the state of California in a range of hydroclimate metrics critical to water management, using data from 10 statistically downscaled global climate model and two emissions scenarios currently used by the state. We find substantial inter-model agreement under both emissions scenarios-and $>80 \%$ inter-model agreement under the more severe climate change scenario-across metrics that collectively point toward an increasingly volatile, temporally concentrated, and extreme precipitation future for the state. We show, via hydrologic and operations modeling, that accounting for shifts in these more nuanced metrics reduces the projected reliability and sustainability of current water management practices to a greater degree than would be inferred from changes in total annual precipitation alone. These results highlight both the viability and critical importance of incorporating climate change projections quantitatively into water management decisions in California and other regions vulnerable to hydroclimate shifts, and underscore the need to develop integrated climate-hydrologic-operations models and decision-making protocols capable of accounting for all projected hydroclimate shifts.
\end{abstract}

Keywords Climate change $\cdot$ Water $\cdot$ California $\cdot$ Hydroclimate $\cdot$ Climate models $\cdot$ Downscaling

\section{Introduction}

California's hydroclimate conditions have shifted since the mid-twentieth century, generating severe management challenges for the state's highly engineered water storage and

Electronic supplementary material The online version of this article (https://doi.org/10.1007/s10584-02002882-4) contains supplementary material, which is available to authorized users. 
conveyance system and its groundwater reservoirs. Annual mean temperatures have increased by $2{ }^{\circ} \mathrm{C}$ statewide (Bedsworth et al. 2018), springtime snow water storage has declined by $10 \%$ (Mote et al. 2018), and the proportion of wintertime precipitation falling as snow has decreased statewide (Knowles et al. 2006). The state's 2012-2016 drought-its most intense in a millennium (Griffin and Anchukaitis 2014) — had drastic consequences for drinking water access, economic activity, and agricultural productivity. Although natural variability played a role in the drought's development (Mao et al. 2015; Williams et al. 2015), anthropogenic climate change intensified snowpack losses (Berg and Hall 2017), moisture deficits (Diffenbaugh et al. 2015; Williams et al. 2015), and the overall atmospheric patterns that contributed to the drought's persistence (Swain et al. 2014; Wang et al. 2014). The drought's intensification of long-term groundwater overdraft to record levels led to critical water supply loss for rural communities (Lund et al. 2018). Consequently, in 2014, the state passed the Sustainable Groundwater Management Act (SGMA) requiring overdrafted groundwater basins to achieve sustainability by the 2040s (Langridge et al. 2018). Shortly thereafter, record-breaking 2016-2017 winter precipitation and flooding yielded significant infrastructure impacts —including the Oroville Dam crisis in early 2017 (White et al. 2018; Huang et al. 2018)—yet did not substantially replenish key groundwater reservoirs (Langridge et al. 2018).

Despite the severe societal impacts of hydroclimate shifts, simulating impacts of climate change on regional hydroclimate remains a major challenge in the climate modeling community. Comprehensive assessments of regional hydroclimate behavior in global climate models (GCMs) have primarily focused on gross precipitation metrics, such as annual and monthly means and totals (Bedsworth et al. 2018; DWR 2019; Christensen et al. 2013), which remain highly uncertain. Spatially coarse-resolution GCMs, even when downscaled and bias-corrected to higher regional resolutions, project both increases and decreases in total annual precipitation in California (Supplementary Fig. 1). Though use of climate data is increasing in the water sector, this uncertainty in gross regional precipitation metrics has been interpreted in certain planning and policy contexts as precluding meaningful quantitative integration of climate projection data into water planning, as discussed for instance by Schwarz et al. (2018) and Ray et al. (2020) study. For example, one groundwater sustainability plan submitted under SGMA cites the "conflicting results" on total precipitation changes in coarse-resolution GCMs as motivation to use an unmodified historical precipitation record as its expectation for future basin-wide precipitation conditions (IWVGA 2020), similar to issues identified in other plans submitted (Christian-Smith et al. 2017).

However, process-level studies of future climate projections indicate a range of more complex shifts in California hydroclimate that have substantial and, in many cases, stronger implications for regional water management. Coarse-resolution GCM studies project increased frequency of both extremely wet and extremely dry years (Berg and Hall 2015; Swain et al. 2018) due to climate change. Multiple studies indicate future increases in extreme and heavy precipitation in California (Gershunov et al. 2019; Polade et al. 2017). There is widespread and long-standing consensus on drastic snowpack loss with future climate change across modeling techniques and emissions scenarios (Bedsworth et al. 2018; Fyfe et al. 2017; Gleick 1987; Knowles and Cayan 2004; Lettenmaier and Gan 1990; Sun et al. 2015, 2019). Previous generations of GCM output, meanwhile, demonstrated risk of increased flood flows and changing seasonality of streamflows (Das et al. 2011a, 2011b, 2013) and precipitation (Pierce et al. 2013a). 
These hydroclimate statistics are generally considered to be stronger determinants of operational challenges and negative impacts to water users than long-term trends in annualor monthly-mean precipitation, but have not been quantitatively incorporated into most longterm water management planning at the state to local level historically (Bedsworth et al. 2018). The future behavior of these management-relevant statistics can be - in a number of important contexts - entirely obscured by analysis of climate model projections narrowly focused on annual or even monthly total or average precipitation changes (e.g., Swain et al. 2018). Detailed efforts at quantitative climate data incorporation are present in the water sector (e.g., Groves et al. 2015; Park et al. 2019; Ray et al. 2020; Steinschneider et al. 2019) and represent an important advancement over decision-making based on the historical record, but, with few exceptions, have not yet resulted in integration of climate projection data that accounts for hydroclimatic shifts beyond mean annual or monthly precipitation and temperature shifts into water decision-making. Operating rules of many key California surface reservoirs continue to be based on statistics of reservoir inflow intensity and timing from early twentieth-century observations (Eum et al. 2012). Climate change incorporation in groundwater sustainability planning, while mandated by the recent SGMA regulation, is not required to be quantitative, and non-binding state guidance documentation focuses primarily on accounting for mean-state shifts in precipitation (SGMP 2018). Increased integration of relevant climate projection data as part of a holistic water management strategy is likely to reduce risks to water security.

In this study, we focus on assessing a range of hydroclimate statistics that map to impacts on water management within the suite of GCM data currently used in state-level assessments and guidance documents (section 3.1). We investigate the impact of accounting for these shifts on key water management outcomes (section 3.2-3.3) and show that their inclusion substantially changes those outcomes, even in the absence of changes in total annual precipitation. These findings point to a need for improved integration of climate planning in California's water management, including (1) more sophisticated incorporation of climate projection data into water management and (2) the development of hydrologic and planning models, as well as decision-making protocols, that are capable of accounting for the full range of hydroclimate shifts that are projected for the state (section 4). The robustness of the findings for the complex hydroclimate of California suggests that such analysis is warranted in other regions with similar water supply challenges across the Western USA and Mediterranean climates worldwide.

\section{Data and methods}

We focus on the behavior of a range of inter- and intra-annual hydroclimate statistics that have historically determined the viability of key regional water management strategies (section 2.1) in the suite of climate model data most widely used by the state of California (section 2.2). At present, no statewide water resource planning model is configured to simulate impacts of the full suite of these non-mean state shifts on the viability of water systems operations. To assess the importance of accounting for these shifts in water management, we therefore select two illustrative quantitative case studies - one focused on the impact of extreme daily precipitation climate shifts on groundwater sustainability (section 2.3) and one focused on the impact of seasonality shifts on the reliability of surface reservoirs (section 2.4). 


\subsection{Definition of hydroclimate metrics}

\subsubsection{Intra-annual hydroclimate metrics}

Based on downscaled GCM output (section 2.2), we calculate a range of hydroclimate metrics characterizing precipitation dynamics within a given water year. These include (1) the concentration of precipitation into the climatologically wet cool season months (NovemberMarch), (2) the fraction of total precipitation occurring as rain versus snow, (3) the total snow water equivalent (SWE), (4) the frequency of rain-on-snow events, (5) the maximum 3-day precipitation, (6) the concentration of precipitation into extreme days, and (7) the total evapotranspiration. The first 3 metrics collectively encapsulate the changing viability of the snowpack/surface reservoir model of western water management. The next three hydroclimate metrics are drivers of flood risk and serve as indicators of potential high-frequency streamflow variability-which directly informs the level of short-term retention and storage required to effectively utilize streamflow and runoff. Finally, total evapotranspiration provides a metric of the combined effects of temperature, moisture availability, and atmospheric water demand on loss of water to the atmosphere. Full details on the calculation of each metric are provided in the Supplementary materials.

We calculate these metrics at each grid point, in the state average, and averaged over the 11 California climate regions (Abatzoglou et al. 2009; Supplementary Fig. 37; Supplementary Tables 1-2). We assess the change in each intra-annual metric between present-day (20062035) and end-of-century (2070-2099) conditions as simulated by a given GCM.

\subsubsection{Inter-annual hydroclimate metrics}

In addition to within-year hydroclimate behavior, both extremely wet and extremely dry years, as well as their sequencing in time, can stress water management and infrastructure. The recent sequencing of extremely dry years (2011-2016) followed by an extremely wet year (2016-2017) in California, for instance, resulted in increased flood and landslide risk (Kean et al. 2019; Oakley et al. 2018). Following the methodology of Swain et al. (2018), we characterize the degree of precipitation volatility as captured by the frequency of very wet and very dry winters - calculated as the number of years with November-to-March total precipitation above the 80th percentile and below the 20th percentile of historical (19502005) precipitation, respectively - and by the frequency of very wet winters followed by very dry winters or vice versa. For each inter-annual metric, we calculate the change between historical (1950-2005) and late-century (2044-2099) conditions as simulated by each GCM. The time periods used for this analysis differ from those used in the intra-annual analysis (section 2.1.1) because a longer time series is necessary to establish a sufficient sample size for inter-annual metrics.

\subsection{Analysis of downscaled global climate model data}

We assess the above metrics in $10 \mathrm{GCMs}$, downscaled to 1/16th degree longitude by latitude over California and bias-corrected using the Localized Constructed Analog (LOCA) method. The 10 LOCA-downscaled GCMs are those identified by the California Climate Change Technical Advisory Group (CCTAG) as having the highest skill at simulating key aspects of California's climate and are, therefore, those used in the 4th California Climate Assessment 
(Pierce et al. 2018). Full details on the LOCA methodology can be found in Pierce et al. (2014). Within the LOCA dataset, we characterize inter-model agreement (e.g., Figs. 2, 3) by assessing the number of models that produce changes of the same sign as the model-mean change, similar to hydroclimate inter-model agreement metrics used by the IPCC (Kirtman et al. 2013). Individual model simulation of metrics is shown in Supplementary Figs. 15-32. Where we refer to "universal" inter-model agreement, 10 out of the 10 models analyzed produce shifts of the same sign. Where we refer to "strong" inter-model agreement, at least 8 out of the 10 models analyzed produce shifts of the same sign. While inter-model agreement on sign of change on its own may not be sufficient to inform all management decisions, we view agreement on directionality of key hydroclimate shifts as sufficient to encourage increased use of climate data in water decision-making.

We opt to use the LOCA dataset here primarily due to its wide adoption in state climate assessments and guidance documentation (e.g., Bedsworth et al. 2018; DWR 2019; SGMP 2018), and secondarily due to its relatively higher fidelity at capturing shifts in extremes compared with other downscaled climate datasets (Pierce et al. 2014, 2015). Other statistical, dynamical, and hybrid downscaling methods have been applied to GCM data over California to varying degrees of success (e.g., Hidalgo et al. 2008; Mearns et al. 2009; Walton et al. 2015; Wood et al. 2002). The LOCA methodology is designed to improve retention of the changes in extremes projected by climate models, while maintaining greater computational efficiency than dynamical downscaling (Hagemann et al. 2011; Pierce et al. 2013b, 2015) - which may contain residual biases from the regional climate models used.

The substantial validation, widespread use, and public accessibility of the LOCA dataset make it a particularly important one in which to demonstrate and test the importance of climate shifts critical to California water management. Existing LOCA validation (Pierce n.d.; Vano et al. 2020) demonstrates minimal error between observations and the downscaled GCM representation of historical precipitation, minimum and maximum temperature, and diurnal temperature range (which are used to train the downscaling and bias correction of the models) and minimal systemic bias between the coarse-resolution and downscaled GCM output. Biases in the particular metrics analyzed in this study are also generally minimal and non-systemic (see Supplementary materials for a full discussion). The notable exception is at high elevation, where a minority of models overestimates SWE and simulation of the driest 20th percentile of winters is wetter in the majority of models than what manifested in the historical record.

The LOCA dataset provides downscaled GCM data for only the RCP 8.5 scenario, a "high warming" scenario standardized by successive IPCC reports (van Vuuren et al. 2011), and the RCP 4.5 emissions scenario, a "medium stabilization" scenario, though additional scenarios are available in the CMIP5 coarse-resolution GCM archive. We focus on results using RCP 8.5 downscaled data (see Supplementary materials for full discussion of the choice of emissions scenario), but provide equivalent assessment of all metrics calculated here for LOCA-downscaled GCM data using the RCP 4.5 emissions scenario (see Supplementary Figs. 13 and 14 and Supplementary Table 2). Although perturbations and signal-to-noise ratios are generally smaller under RCP 4.5 than RCP 8.5 assumptions, the key conclusions of our analysis hold under both emissions scenarios. Without substantial additional policy to reduce greenhouse gas emissions, the end-of-century shifts identified in both scenarios here are expected to manifest, though the particular timing will depend on how rapidly emissions grow in reality and on the true sensitivity of the climate system to greenhouse gas emissions (Forster et al. 2020; Hausfather and Peters 2020). 


\subsection{Application to regional groundwater sustainability}

As a case study on the implications of shifts in hydroclimate statistics on groundwater management, we assess the impact of a sample hydroclimate metric on groundwater budget behavior in Northern California's Scott Valley, using the Scott Valley Integrated Hydrologic Model (SVIHM; Tolley et al. 2019). The region was selected based on the availability of the open-source SVIHM model, the presence of groundwater-dependent agriculture and ecosystems, and minimal availability of imported water. The integrated SVIHM model consists of three cascading sub-models: a streamflow regression model, soil water budget model, and groundwater-surface water model. Additional information on the Scott Valley basin and the formulation, calibration, and validation of SVIHM is provided in the Supplementary materials.

Using a historical differencing analysis, we focus on impacts of changes in extreme precipitation statistics on the groundwater budget of Scott Valley, while holding constant all other meteorological conditions and the availability and cost of surface and groundwater for irrigation. This is a simplification of the consequences of predicted changes in hydroclimate relevant to this region, which include shifts in evapotranspiration and snowpack, but allows us to isolate the effects of change in a single statistic whose impact on groundwater sustainability has had a relatively less coverage in the existing literature than statistics like mean annual rainfall or snowmelt timing (e.g., Alam et al. 2019; Langridge et al. 2018). The change in the proportion of annual precipitation falling on extreme days (section 2.1.1), as simulated under RCP 8.5 conditions in the LOCA climate data (section 2.2), is used as a basis to modify the historical inputs to SVIHM, which consists of historical hydrologic data for 1991-2018. Daily precipitation is redistributed within each water year to achieve a $35 \%$ increase in the fraction of annual precipitation occurring in the $5 \%$ most extreme precipitation days for each year, while holding total annual precipitation fixed at its historical value (Supplementary Figs. 34 and 35; see Supplementary materials for additional details). This increase is designed to test the upper end of RCP 8.5 projections in the LOCA data for Scott Valley for this metric, which range from a $0-38 \%$ increase with a mean of $12 \%$. We then assess change in behavior of water budget elements between this altered precipitation simulation and a simulation forced with the baseline historical inputs to SVIHM from 1991 to 2018.

\subsection{Application to reservoir operations}

As an illustrative case study of the effects of change in hydroclimate statistics on surface water operations, we characterize the influence of shifting monthly hydroclimate statistics on Oroville Reservoir, the SWP's largest reservoir, based on outputs published and validated by Knowles et al. (2018). They project future unimpaired and impaired hydrology, reservoir storage, and downstream managed flows in the Sacramento and San Joaquin basins based on the same climate projection data used in this study, but aggregated at certain analysis steps to relatively coarse (monthly) temporal resolution (see Supplementary materials for additional details). The simulations assume that reservoir operations are held fixed into the future under the currently used rule curves. The study produced monthly data on storage for individual reservoirs in the two basins and monthly and resampled daily data on managed reservoir outflows under the RCP 8.5 and RCP 4.5 future emissions scenarios in the 10 LOCAdownscaled GCMs used here.

We overlay this data with an analysis of how the simulated climate shifts will impact the long-term ability of Lake Oroville to serve its current water supply and flood control role. We 
use these outputs to assess monthly storage behavior at Lake Oroville at end-of-century (2070 2099) under RCP 8.5 versus historical (1980-2009) conditions and compare it with changes in reservoir outflows. Note that this historical baseline differs from that used to assess the intraannual and inter-annual metrics within the LOCA dataset (sections 2.1 and 2.2), and reflects the historical definition used by Knowles et al. (2018). Publicly available hydrologic and resource planning models available for the state of California are currently limited to monthly time steps, precluding quantitative assessment of the impact of predicted changes in daily hydroclimate statistics (e.g., change in maximum 3-day precipitation) that we assess as part of this study. We therefore qualitatively combine the modeled shifts in monthly Oroville Reservoir operations with information on operational limitations and sub-monthly climate shifts identified in our LOCA analysis (but not included in the model setup used by Knowles et al. (2018)) to assess how the operations changes and the outlook of future reservoir function would be further impacted by expected sub-monthly hydroclimate shifts.

\section{Results}

\subsection{Critical shifts in California hydroclimate}

Our analysis demonstrates strong agreement among climate models on unfavorable shifts in a range of hydroclimate characteristics on which California water management is predicated, despite continued uncertainty regarding future changes in statewide total annual precipitation (Supplementary Fig. 1). In particular, the hydroclimate statistics assessed here point to high certainty on a shift toward precipitation (1) arriving increasingly in liquid form (rain vs. snow) and with greater intensity, (2) concentrated more narrowly into the climatologically wet winter months, and (3) characterized by increased year-to-year volatility between overall dry and wet water years. While patterns are more coherent in the more severe RCP 8.5 scenario, agreement emerges in both emissions scenarios.

Models agree universally in both emissions scenarios on an increase in the fraction of total yearly precipitation falling as rain rather than snow, necessitating greater flexibility of storage and management of rainwater (Fig. 1d, Supplementary Fig. 13d, Supplementary Fig. 33d). Notably, downscaled LOCA data from all models shows an increase in excess of $75 \%$ in RCP 8.5 and $40 \%$ in RCP 4.5 in the rain versus snow fraction across much of the Sierra Nevada and southern Cascades. This coincides with universal projected snowpack loss (up to 100\% loss across many parts of the state in both scenarios; Fig. 1g, Supplementary Fig. 13g, Supplementary Fig. 33g).

Models also agree under RCP 8.5 end-of-century conditions on a compression of yearly precipitation into (a) extreme events, and (b) into the winter (vs. autumn/spring) season - with implications for the growing need to simultaneously manage flood and drought risk. Models simulate an increase exceeding $15 \%$ across central California in the fraction of yearly precipitation that arrives in the form of extreme ( $>95$ th percentile of daily precipitation) events (Fig. 1a), and 8 of 10 models show an increase in state-averaged extreme precipitation (Supplementary Fig. 33a). Changes in maximum 3-day precipitation are generally smaller and exhibit weaker inter-model agreement (Fig. 1b, Supplementary Fig. 33b). Areas of strong inter-model agreement in both of these extreme metrics, however, tend to coincide with regions of high climatological precipitation levels (see Supplementary Fig. 2). The fraction of total yearly precipitation arriving between November and March also increases, with strong 
a) $\Delta$ Fraction of yearly precip. on extreme days (\%)

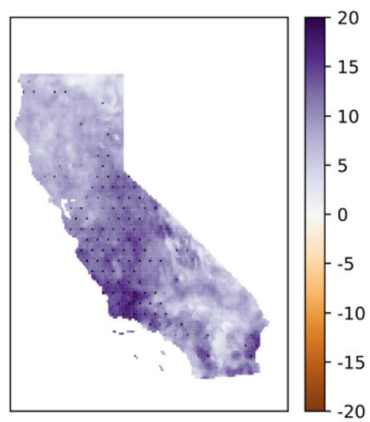

d) $\Delta$ Ratio of yearly precip. as rain vs. snow (\%)

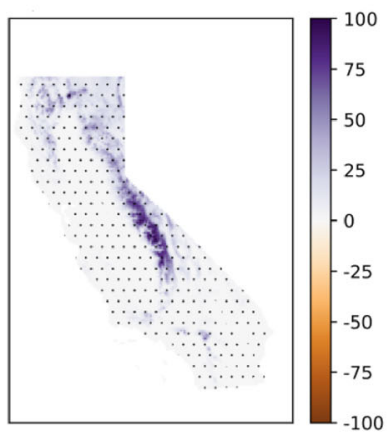

g) $\Delta$ Cumulative snow water equiv. (\%)

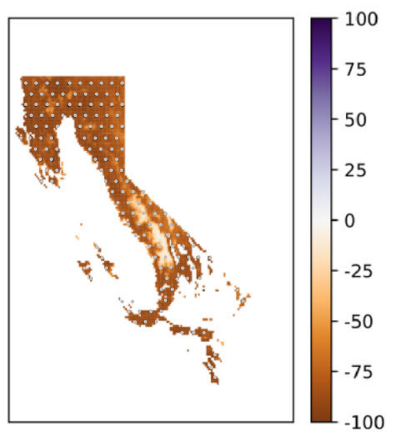

b) $\Delta$ Maximum three-day precip. (\%)

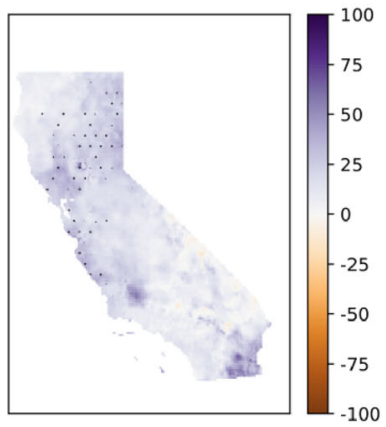

e) $\Delta$ Number of rain-onsnow days (\%)

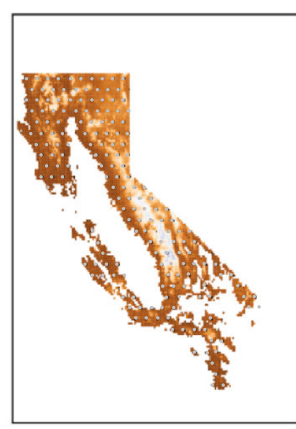

c) $\Delta$ Fraction of yearly precip. in November-March (\%)

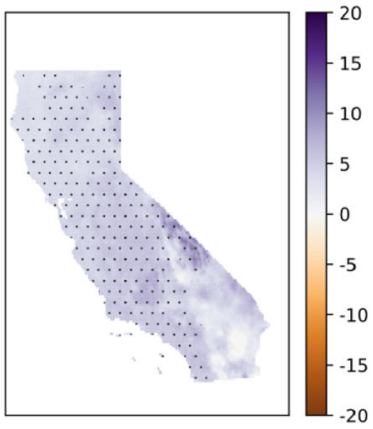

f) $\Delta$ Normalized \# of rainon-snow days (\%)
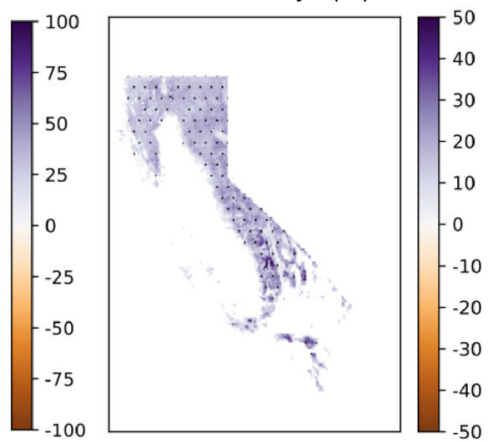

h) $\Delta$ Evapotranspiration (\%)

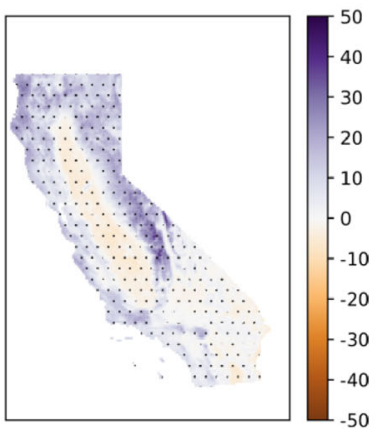

Fig. 1 Spatial patterns and level of inter-model agreement of changes in intra-annual statistics. The 10 GCMs assessed show strong agreement across much of the state in (a) fraction of total annual precipitation falling on extreme (>95\% percentile) days, (b) maximum 3-day precipitation, (c) fraction of total annual precipitation falling between November and March, inclusive, (d) ratio of total annual precipitation falling as rain versus snow, (e) number of rain-on-snow days, (f) number of rain-on-snow days normalized by days with snow water equivalent greater than 0 , (g) cumulative annual snow water equivalent, and (h) cumulative annual evapotranspiration. Values shown are for percent changes between present-day (2006-2035) mean and RCP 8.5 end-ofcentury (2070-2099) mean conditions relative to present-day conditions. Stippling indicates regions where over $80 \%$ of the models agree on the sign of change 
a) $\Delta$ Frequency of wet years (\%)

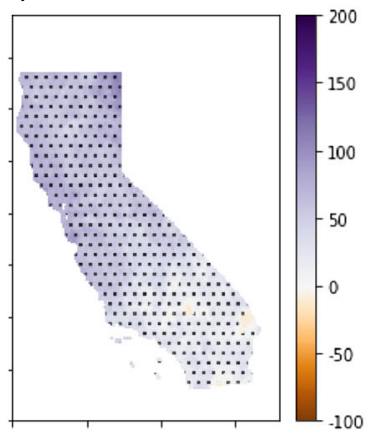

d)

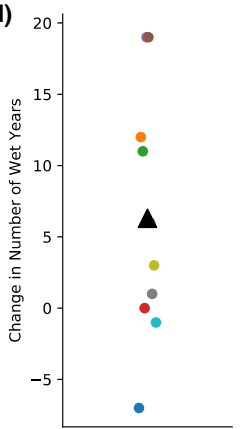

A Multi-Model Average b) $\Delta$ Frequency of dry years (\%)

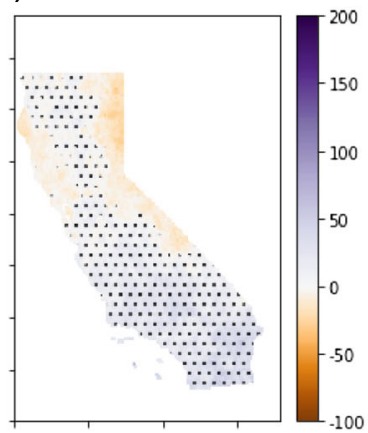

e)

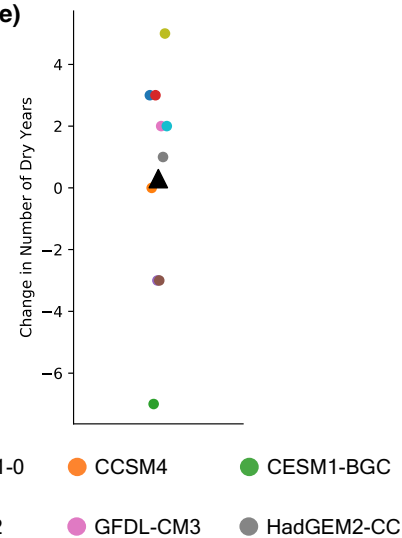

c) $\Delta$ Frequency of whiplash (\%)

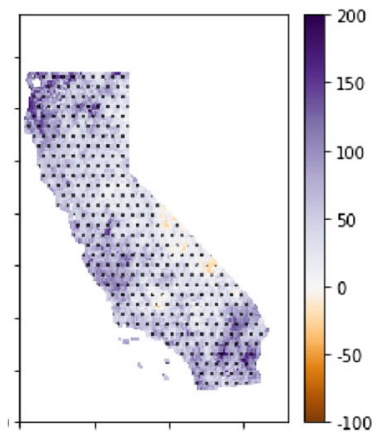

f)

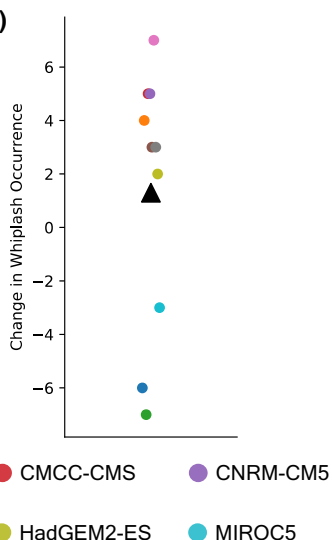

Fig. 2 Spatial patterns, state-averages, and level of inter-model agreement of changes in inter-annual statistics. Spatial patterns and levels of inter-model agreement across the 10 GCMs are shown for (a) frequency of wet year occurrence, (b) frequency of dry year occurrence, $(\mathbf{c})$ frequency of year-to-year whiplash (wet years immediately followed by dry years or vice versa). Inter-model agreement calculated based on statewide average thresholds is also shown (d, e, f) (horizontal displacement added to increase visibility of overlapping data points). Values shown are for percent changes between historical (1950-2005) mean and RCP 8.5 late-century (2044-2099) mean conditions relative to historical. Stippling in a-c indicates grid cells in which over $80 \%$ of the models agree on the sign of change

inter-model agreement across the entire state other than the Mojave Desert in the southeast (Fig. 1c, Supplementary Fig. 33c), where the seasonal pattern of climatological rainfall differs from the rest of the state. Given the uncertain, but generally minimal, projected changes in total annual precipitation (Supplementary Fig. 1), this temporal concentration of precipitation across multiple timescales also indicates more intense intervening dry periods during which water demand in both human-managed and natural systems will rise. Notably, this agreement is not yet present by end-of-century under RCP 4.5 conditions (Supplementary Fig. 13a-c), suggesting that these shifts may be more difficult to discern in lower warming scenarios due to the low signal-to-noise ratio created by intrinsically large background climate variability in this region. However, universal inter-model agreement on increased evapotranspiration across much of the state (Fig. 1h, Supplementary Fig. 13h. Supplementary Fig. 33h) also indicates a substantial increase in water demand in both scenarios.

We also assess changes in the frequency of rain-on-snow events, which have historically been drivers of major flood-related water management stress (Davenport et al. 2020). Because 
of the drastic declines in snowpack coverage projected by all models in both emissions scenarios, the absolute number of rain-on-snow days also declines universally across the models and across the state in both emissions scenarios (Fig. 1e, Supplementary Fig. 13e, Supplementary Table 1, Supplementary Table 2, Supplementary Fig. 33e). However, when normalized for the presence of snow (i.e., when the number of days with rain occurring on snow is normalized by the number of days when snow is present), the frequency of these events increases with strong inter-model agreement statewide in both scenarios (Fig. 1f, Supplementary Fig. 13f, Supplementary Fig. 33f). This indicates that, although the overall risk of rain-on-snow events is likely to decline, during periods when snow is present, the risk of these events could increase substantially.

Projected changes in inter-annual volatility of precipitation present a more nuanced picture, but indicate that year-to-year swings between wet and dry water years will increase. On a grid-cell-by-grid-cell basis, there is a strong agreement in increased frequency of both wet years (Fig. 2a, Supplementary Fig. 14a) and dry years (Fig. 2b, Supplementary Fig. 14b) in both emissions scenarios. There is also widespread intermodel agreement in increased frequency of overall whiplash between dry and wet years (i.e., a wet year followed by a dry year or vice versa; Fig. 2c, Supplementary Fig. 14c) in both scenarios. In RCP 8.5, the likelihood of these events as much as triples across parts of Northern California, the Central Coast, and the Mojave Desert, with most regions experiencing an increase of greater than $50 \%$. The magnitude of shifts is generally smaller in RCP 4.5, as expected given the lower degree of warming, but retains the directionality and pattern of the RCP 8.5 changes.

There is lower, but still majority, inter-model agreement when the dry (below the 20th percentile) and wet (above the 80th percentile) year thresholds are calculated in terms of stateaveraged precipitation rather than at each grid cell. Seven out of ten models in RCP 8.5 and eight out of ten in RCP 4.5 show an increase in the number of statewide wet years (Fig. $2 \mathrm{~d}$, Supplementary Fig. 14d). The change in the number of statewide dry years is more mixed across models and smaller in the model-mean, though the majority of models (6 of 10 in RCP 8.5 and 7 of 10 models in RCP 4.5) project an increase in statewide dry years (Fig. 2e, Supplementary Fig. 14e). The increase in statewide occurrence of whiplash between very wet and very dry years or vice versa, meanwhile, is robust in RCP 8.5 (7 of 10 models; Fig. 2f) but inconclusive in RCP 4.5 (5 of 10 models; Supplementary Fig. 14f).

We note that aspects of these results are consistent with those in Swain et al. (2018) — who also found a larger, geographically widespread, and more statistically robust increase in extremely wet years than in extremely dry years under RCP 8.5 conditions. Swain et al. (2018) also reported a large, geographically widespread, and statistically robust future increase in dry-to-wet whiplash, though they did not assess total whiplash (i.e., both dry-to-wet and wet-to-dry whiplash) as done here.

The societal impacts of dry-to-wet versus wet-to-dry whiplash events may not be symmetric. For example, extremely wet conditions following prolonged dry spells have caused severe runoff and debris flow impacts due to the prevalence of large wildfire burn scars and desiccated soils (Oakley et al. 2018). On the other hand, sudden transitions from wet to dry conditions, as occurred in Northern California from winter 2016-2017 to summer 2017, can amplify wildfire risk due to the proliferation and subsequent rapid drying of fine fuels (grasses and brush). However, the relatively small sample size and short time series provided by the LOCA data limits its utility for assessing changing frequency of individual types of whiplash (see Supplementary materials for additional discussion). 


\subsection{Reductions in groundwater sustainability from shift in extremes}

Our case study of Northern California's Scott Valley demonstrates the impact of the shift toward increased extreme precipitation projected by GCMs under RCP 8.5 conditions on groundwater sustainability. We find that, although this shift may have minimal effects on total budgets over a long-term average, it can meaningfully impact predicted water use behavior and the sustainability of groundwater budgets during certain water years, even without changes in total annual precipitation.

When the increased concentration of annual precipitation into extreme days seen in the GCM projections is mimicked in the altered rainfall scenario, the key water budget components of recharge and surface and groundwater irrigation increase (Fig. 3). All three of these budget terms are greater in the altered scenario than those in the historical scenario in each water year in the 28-year simulation period. The explanation for an increase in recharge is straightforward: in the altered, more extreme scenario, the volume of water arriving on days when crop evapotranspiration demand is already met increases. Thus, more water infiltrates through the root zone on wet days. The increase in irrigation terms is somewhat less intuitive. Because the total annual precipitation is held fixed between the altered and historical simulations, the increase in precipitation on extremely wet days is counterbalanced by a corresponding decrease in precipitation on all other rainy days. This results in an increase in the number of drier days on which soil water is lower than plant demand, which triggers the application of additional irrigation water.

The increase in water budget terms occurs to different degrees during different water years, and the strongest predictor of the degree of increase is the original concentration of the rainfall in time. This is illustrated by water years 2010 and 2015 (Fig. 3). Both years received a total

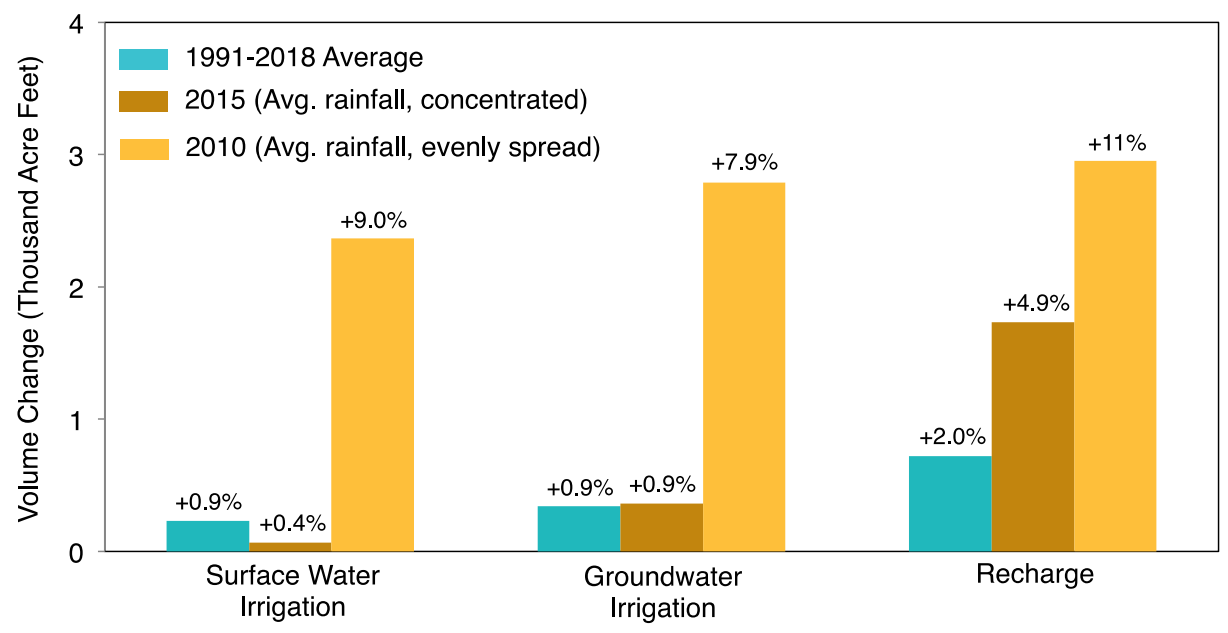

Fig. 3| Changes in groundwater budget terms due to increased extreme precipitation. Water use behavior in the California Scott Valley shows higher sensitivity to redistribution of annual precipitation toward extreme days in a water year with evenly spread precipitation (2010, yellow) than one with wintertime concentrated precipitation (2015, dark brown). These two water years experienced total annual precipitation close to the average of the full 1991-2018 period analyzed (blue), illustrating the importance of understanding the impacts of climate shifts on water behavior in individual water years. Column values represent the absolute change between the historical simulation and the altered precipitation simulation. Numbers shown above columns indicate the percent change relative to the historical simulation 
annual depth of rainfall near the average for the historical time series, but the degree of temporal concentration was greater in 2015 than 2010 (maximum rainfall density of $36 \%$ of annual in 30 days in 2015, and 25\% of annual in 2010; Supplementary Fig. 34). We hypothesize that the more evenly spread rainfall in 2010 is relatively vulnerable to disruption by increased frequency of extremes. Conversely, in 2015, the rainfall concentration is already relatively extreme, so the rainfall redistribution has a smaller impact on the additional number of days when irrigation was necessary. This highlights the need for high spatiotemporal resolution understanding of climatological water supply, projected hydroclimate shifts, and water use behavior in order to constrain groundwater sustainability under climate change.

These results likely represent a conservative estimate of the sensitivity of groundwater basins to such hydroclimate shifts. Many regions are projected to experience substantially larger increases in the fraction of precipitation falling during extreme events than Scott Valley under RCP 8.5 conditions (Fig. 1a). Many of the regions containing basins categorized as critically overdrafted by the California Department of Water Resources (DWR 2015) lie in regions like the San Joaquin Valley where shifts in extreme precipitation are projected to be 5-10 times greater than those in Scott Valley. Additionally, by design, the simulations tested here do not incorporate changes in temperature and atmospheric evaporative demand that are expected to lead to increased evapotranspiration rates with future climate change (e.g., Fig. 1h) or other hydroclimate shifts, which are projected to further stress groundwater sustainability. Alam et al. (2019), for example, identify an average 31-39\% increase in groundwater loss rate in the California Central Valley due to climate changes in monthly hydroclimate statistics, though they do not assess the sub-monthly hydroclimate shifts assessed here. The emergence of groundwater budget sensitivity to temporal precipitation distribution that we demonstrate here for the Scott Valley groundwater basin is therefore a strong indicator of likely sensitivity in more heavily impacted basins.

\subsection{Reduced reservoir storage from changing inflow and seasonality dynamics}

Our case study of Lake Oroville, currently the largest storage facility in the California State Water Project, illustrates the impact of shifts in monthly precipitation statistics on storage dynamics and the extent to which these shifts are likely to reduce storage reliability. Figure 4 shows the change in Lake Oroville's monthly storage and outflow conditions under end-ofcentury (2070-2099) RCP 8.5 conditions versus historical (1980-2009) conditions. These changes reflect several of the monthly precipitation metrics assessed in this study-including changes in the concentration of wintertime precipitation, precipitation type, and evapotranspiration - but not those associated with daily precipitation statistics, such as changes in 3-day maximum precipitation, rain-on-snow event frequency, or concentration of extreme precipitation.

Our analysis indicates a substantial reduction in the ability of Lake Oroville to provide storage capacity under RCP 8.5 conditions due to these monthly shifts alone. Storage declines by roughly $17 \%$ averaged over the year, and losses are greatest in the months in which climatological storage in the reservoir is lowest (>35\% in September and October; Fig. 4). This indicates that the storage losses will intensify the seasonal cycle of water availability in addition to decreasing availability overall. The loss of storage occurs despite an overall increase in inflows (Knowles et al. 2018) and a small model-mean increase in overall precipitation over the catchment area (Supplementary Fig. 1; Knowles et al. 2018). 


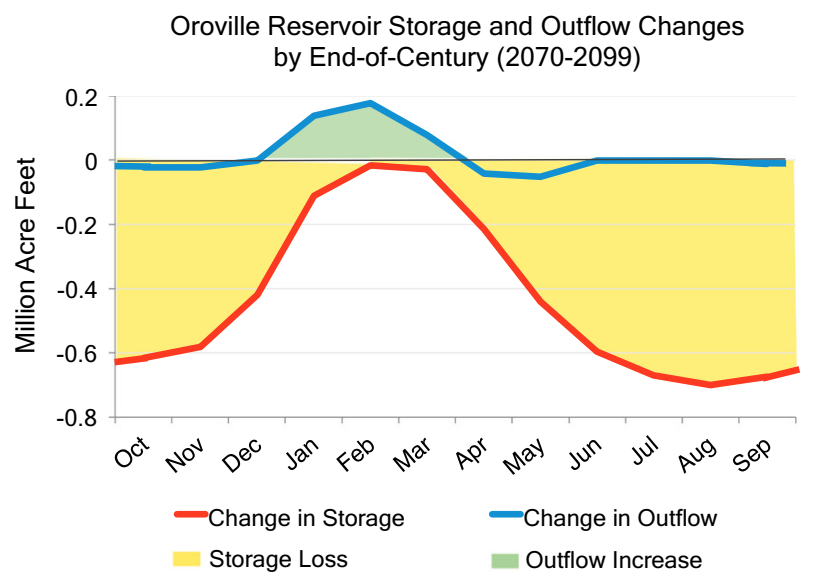

Fig. 4 Changes in Oroville storage and outflows due to climate change. Lake Oroville shows substantial changes in monthly-mean storage seasonality and amount (red curve) and reservoir outflows (blue curve) due to monthlymean climate changes between historical (1980-2009) and RCP 8.5 end-of-century (2070-2099) conditions

Long-term trends in storage are impacted by how effectively the reservoir can retain water given the timing of inflows relative to when the competing demands of flood prevention and water supply must be met. The reduction in storage is driven largely by concentration of inflows into the already wet winter months (Knowles et al. 2018), when currently used reservoir operations rules (which are held fixed in the simulations) require excess flows to be released for flood protection purposes. This hydrologic signal aligns with the 5-10\% increase in concentration of precipitation into November-March across the entirety of Oroville's catchment area seen in our analysis of the LOCA output (Fig. 1c) and also captures monthly-mean shifts in the timing of snowmelt driven by increasing wintertime temperatures as simulated by RVIC (see Supplementary materials). The increased concentration of inflows and consequent requirement for increased wintertime releases is reflected in the increase in outflows in January-March (Fig. 4). The resulting reduction in annual average storage is aligned with other studies that show similar reductions in Oroville carryover storage under future climate conditions (Ray et al. 2020).

Because the modeling setup used by Knowles et al. (2018) assumes that reservoir operations will not be modified in the future, it is possible that some portion of the projected storage losses could be regained by modifying the reservoir's operating rules to allow for additional storage of wintertime inflow. However, storing the increased February outflows (0.18 MAF), for example, would require use of approximately $30 \%$ of the average Oroville reservoir capacity currently reserved for flood control in February (US Army Corps of Engineers 1970) thereby increasing operational risks of catastrophic dam overtopping. Additionally, the model framework used here does not simulate the impact of changing risk of extreme multi-day precipitation events on reservoir management, which our analysis indicates increases by $20 \%$ or more across most of Oroville's catchment area (Fig. 1 a and b) under RCP 8.5 conditions, and which would necessitate an increase rather than decrease in the reservoir capacity held empty to protect against flood (see also section 4). These factors, along with regulatory barriers to reservoir reoperations (e.g., Shibatani 2015), indicate that modifying reservoir operations may not be sufficient to regain the projected loss of storage and summertime water availability at Oroville under a more severe future trajectory of climate change. 


\section{Implications for water management and decision-making}

The analysis presented here has multiple implications for regional water management under climate change and for the generation of climate projection information and its integration into water decision-making processes, both in California and in a broader context. The inter-model agreement on critical hydroclimate shifts assessed here indicates major challenges to the traditional model of Western US water management. Our case studies show that directly incorporating this more nuanced range of projected hydroclimate shifts, rather than continuing classical methods that utilize only or primarily statistics of the historical period, is likely to assist in mitigating climate risks to water supply operations and sustainability. The overall findings demonstrate a need for increased investment in tools and processes to expand detailed climate planning in the water sector.

These results show strong model consensus that future precipitation in California will come in fundamentally different forms for which the current water management system is underoptimized, even without substantial or high certainty changes in the total amount of precipitation the state receives. In combination, the shifts projected by climate models imply an increased need for management of liquid-phase precipitation in concentrated time periods. Combined with uncertain (but generally small) projected changes in total annual precipitation (Supplementary Fig. 1), this also implies that intervening dry periods (e.g., between extreme events and between the wet winter seasons) will intensify. Indeed, recent evidence suggests that some of these non-mean state hydroclimate shifts, including drought intensification due to warming (Diffenbaugh et al. 2015; Williams et al. 2015), warming of atmospheric river storms (Gonzales et al. 2019), autumn/spring drying (Swain et al. 2018), and increasing inter-seasonal "precipitation whiplash" (Anenberg et al. 2019), are already well underway.

Without changes in water management strategies, the current California water management system will be less able to capture and utilize future water in these new forms. The projected transition from snow to rain and the attendant loss of snowpack that manifests in both emissions scenarios indicate that the traditional snowpack-surface reservoir-conveyance paradigm of management will be increasingly untenable under climate change - a challenge that is already emerging not just in California but also throughout the American West (Fyfe et al. 2017; Bureau of Reclamation 2016; Wang et al. 2018). The increased risk of rain-on-snow events when snowpack is present - as well as the overall trend toward more intense precipitation with larger-storm total accumulations-will necessitate improved flood management and utilization of reservoir releases to preserve water supply benefits in healthy snowpack years.

Multiple factors point to a need for increased flexibility of storage. Increased year-to-year precipitation volatility and the general increase in precipitation intensity suggest that any additional liquid water capacity must not only be capable of storing increased water volumes for longer periods but must also be able to operate safely under increasingly extreme inflow conditions. The transition from snow to rain may also result in less predictability in the geographic distribution of runoff available for storage. The physical processes underlying the natural snowpack reservoir have historically provided predictability in both the timing and spatial distribution of runoff, since both temperature seasonality and topography constrain where and when snowpack occurs and melts (Kapnick and Delworth 2013; Kapnick and Hall 2010). As precipitation is increasingly delivered as rain rather than snow, the geographic distribution of runoff may become increasingly stochastic (He et al. 2019) — again requiring more distributed and flexible liquid water storage. 
Our case study of Oroville Reservoir (section 3.3) under the severe climate change conditions captured by RCP 8.5 end-of-century shows that the state's second largest reservoir will receive water at less beneficial times, necessitating difficult tradeoffs between maintaining flood control and protecting water supply. Although such impacts will likely be reduced under less severe climate change, the methodology of Knowles et al. (2018) leveraged here does not explicitly account for increases in extreme inflows during relatively short-duration (i.e., submonthly) storm events that could result in additional storage losses relative to the historical baseline. During extremely wet periods, the strict "rule curves" under which California's largest dams operate dictate water releases that sacrifice long-term storage capacity to ensure dam safety and adequate flood control buffers for downstream regions (e.g., Eum et al. 2012). Given an expected increase in peak inflows during storm events (from increased rain vs. snow dominance of precipitation and larger overall watershed precipitation volumes), substantial additional losses of surface reservoir storage capacity are plausible in addition to those we report here - though more research is needed to provide a quantitative estimate.

Collectively, these findings highlight the risks created by inflexibility in surface reservoir siting and capacity, which may be increasingly misaligned with runoff availability as California's precipitation becomes increasingly volatile, temporally concentrated, and extreme. Increased conjunctive use of surface water and groundwater, investments in distributed groundwater recharge, and stormwater capture and reuse all provide opportunities for increased flexibility, liquid water storage, and utilization of flood flows (DWR 2018). In particular, the projected emergence of both increased precipitation intensity (results herein; Swain et al. 2018) and increased surface aridity (e.g., Cook et al. 2015; Williams et al. 2015) highlight the potential promise of practices like flood-managed aquifer recharge (FloodMAR; Ghasemizade et al. 2019) in which "excess" surface water is diverted during (or in anticipation of) flood flow events and transported to designated groundwater recharge basins - allowing dam operators to maintain flood control while bolstering resilience to future drought events via groundwater banking. Ultimately, the design and assessment of California water management strategies must fully account for shifts in non-mean state hydroclimate statistics in ways that accommodate future increases in both flood and drought risk.

Our case studies demonstrate the benefits of enhanced consideration of the full suite of projected hydroclimate shifts in water planning to reduce risks of under- or mal-adaptation to climate change. Our Scott Valley case study indicates that water decision-making that does not account for even modest increases in precipitation intensity is likely to misrepresent key groundwater sustainability metrics, such as total irrigation demand and aquifer recharge. The response of an individual groundwater system to increased precipitation extremity will depend on an array of factors, including types of land use, total aquifer storage capacity, and basinwide soil infiltration rates. However, the sensitivity of key groundwater budget terms demonstrated here for a single basin and metric highlights the importance of a more systematic and comprehensive analysis of the sensitivity of other groundwater basins and to other projected climate shifts not captured by current protocols. Currently, consideration of shifts in daily precipitation statistics is not recommended or facilitated as part of the statewide groundwater sustainability planning under SGMA regulations. Suggested datasets and guidance documentation also do not fully account for shifts in the seasonality of precipitation, precipitation type, or inter-annual variability (SGMP 2018). However, as our analysis demonstrates that even the shift toward more extreme precipitation on its own can markedly reduce the sustainability of the groundwater budget, we argue that this represents a substantial weakness of SGMA implementation in its current form. 
Similarly, there is currently no California state-level resource planning model available capable of capturing the impacts of shifts in daily precipitation statistics - such as the changes in extreme precipitation fraction, 3-day maximum precipitation, or rain-on-snow events identified in this study - on the operations and viability of reservoirs, conveyance, and the state water system in general (Knowles et al. 2018). Major water crises in the last decade, such as the 2017 Oroville Dam spillway failure, resulted from high-intensity, relatively shortduration, and generally warm storm events (Huang et al. 2018; White et al. 2018), which our metrics indicate increase in likelihood with climate change. These concentrated precipitation events also increase the need for flood releases, necessitating new investments to maintain flood protection and utilize flood flows. The absence of publicly available operations and hydrologic models capable of accounting for the shifts in daily precipitation statistics projected by GCMs thus creates a major gap in planning for climate change in the water sector.

The implications of the shifts identified here for water management will vary depending on the lifespan and risk tolerance associated with a given decision. Our results indicate that unfavorable shifts in the ratio of rain versus snow, the amount of snowpack, the risk of rain-onsnow events, evapotranspiration, and year-to-year volatility of precipitation can be reliably expected to emerge within the next 50-80 years under both trajectories of future human emissions currently being considered in state of California planning. Current investments in water infrastructure, which may have a 50-100-year lifespan, can be expected to be subject to these shifts. Agreement in metrics associated with extreme daily precipitation and seasonality of precipitation emerges by end-of-century only in the RCP 8.5 scenario in the dataset used here, and would likely emerge to a lesser extent and/or at a later date on the "stabilized" RCP 4.5 emissions trajectory. However, to the extent that water decision-making should be protective given the societal risks of under-planning, increased consideration of these shifts in water management is warranted.

\section{Conclusions}

The results presented here have important implications for securing water supplies under changing climate conditions and encourage increased interaction between the climate and water management enterprises broadly. As we show here in the context of California's hydroclimate, despite extensive research indicating substantial projected hydroclimate shifts, lingering perceptions of uncertainty and a historic mismatch between the type of water analysis conducted by climate modelers and by regional water managers have limited quantitative inclusion of climate change projections in regional water planning, though promising efforts are emerging (e.g., Ray et al. 2020; Steinschneider et al. 2019). Our analysis demonstrates that, while inter-model agreement for future total annual precipitation changes is low, there is strong inter-model agreement in response to both more and less severe climate change scenarios for key non-mean state shifts that bear more directly on the viability of regional water management strategies. Although our results indicate that the severity and timing of projected shifts will depend on the trajectory of future human emissions, most shifts emerge even under the less severe climate change scenario by end-of-century.

We additionally show that integrating these shifts into hydrologic and resource planning models substantially changes water management metrics, such as groundwater sustainability and reliability of reservoir storage, even in the absence of changes in total precipitation. The results indicate both (1) that quantitatively integrating high spatial and temporal resolution 
climate projection information into regional water infrastructure and management decisions will be necessary in order to anticipate and avoid negative outcomes for water supply reliability and 2) that inter-model agreement on key metrics is sufficient to enable this.

California's water future will be characterized neither by perpetual scarcity nor by widespread abundance. Instead, the region will likely experience both ends of the hydroclimatic spectrum with greater intensity. To accommodate these emerging shifts in regional hydroclimate, dynamic and flexible strategies for managing California's water will be critical in ensuring resilience in a warming world. While the metrics we assess here are motivated by existing examples of water management stress, other valuable metrics certainly exist. This work demonstrates the importance of assessing these decision-relevant metrics, as opposed to gross/mean-state metrics. Such an approach is necessary in order to both reveal additional and/ or unexpected stresses on water management outcomes and to make climate data more usable by and relevant to the water management community.

Acknowledgments The authors thank Mike Dettinger for LOCA validation figures, Noah Knowles for assistance on CASCaDE2 outputs, and Kristina Dahl and Dan Cayan for the review of earlier drafts of the manuscript.

Availability of data and material Localized Constructed Analogs data is publicly available at the Cal-Adapt Data Portal (https://cal-adapt.org/data/download/). The Fifth Coupled Model Intercomparison Project data is publicly available through the Program for Climate Model Diagnosis and Intercomparison (https://esgf-node.llnl. gov/projects/cmip5/). Output from C2-CalSim is available as a US Geological Survey Data Release Product (https://www.sciencebase.gov/catalog/item/5b170442e4b092d9651fcc93). All data used in this study is publicly available or provided within the manuscript.

Code availability Code used to generate figures and calculations based on the publicly available datasets is available from the corresponding authors by reasonable request. Code for the Scott Valley Integrated Hydrology Model is publicly available at https://github.com/UCDavisHydro/SVIHM.

Authors' contributions GP conceived of and coordinated the overall analysis, conducted the analysis of hydroclimate metrics, and wrote the final manuscript with input from all authors. DLS provided input on the design and interpretation of hydroclimate metrics and LOCA data. CK led the design of the case study of Scott Valley with input from GP and conducted the associated analysis. JPOP led the design of the case study of Oroville Reservoir with input from GP and conducted the associated analysis.

Funding Persad and Ortiz Partida were partially supported by a funding from the Water Foundation and Environment Now. Swain was supported by a joint collaboration between the Institute of the Environment and Sustainability at the University of California, Los Angeles; the Center for Climate and Weather Extremes at the National Center for Atmospheric Research; and the Nature Conservancy of California.

\section{Compliance with ethical standards}

Conflicts of interest The authors declare that they have no conflict of interest.

Open Access This article is licensed under a Creative Commons Attribution 4.0 International License, which permits use, sharing, adaptation, distribution and reproduction in any medium or format, as long as you give appropriate credit to the original author(s) and the source, provide a link to the Creative Commons licence, and indicate if changes were made. The images or other third party material in this article are included in the article's Creative Commons licence, unless indicated otherwise in a credit line to the material. If material is not included in the article's Creative Commons licence and your intended use is not permitted by statutory regulation or exceeds the permitted use, you will need to obtain permission directly from the copyright holder. To view a copy of this licence, visit http://creativecommons.org/licenses/by/4.0/. 


\section{References}

Abatzoglou JT, Redmond KT, Edwards LM (2009) Classification of regional climate variability in the state of California. J Appl Meteorol Climatol 48:1527-1541

Alam S, Gebremichael M, Li R, Dozier J, Lettenmaier DP (2019) Climate change impacts on groundwater storage in the Central Valley, California. Clim Change 157:387-406

Anenberg SC, Dutton A, Goulet CA, Swain DL, van der Pluijm B (2019) Toward a resilient global society: air, sea level, earthquakes, and weather. Earths Future 7:854-864

Bedsworth, L., Cayan, D., Franco, G., Fisher, L., and Ziaja, S. (2018). Statewide summary report. California's fourth climate change assessment. (California Governor's Office of Planning and Research, Scripps Institution of Oceanography, California Energy Commission, California Public Utilities Commission)

Berg N, Hall A (2015) Increased interannual precipitation extremes over California under climate change. J Clim 28:6324-6334

Berg N, Hall A (2017) Anthropogenic warming impacts on California snowpack during drought. Geophys Res Lett 44:2511-2518

Bureau of Reclamation (2016) SECURE Water Act Section 9503(c) - Reclamation climate change and water. Bureau of Reclamation, Policy and Administration, Denver

California Department of Water Resources (DWR) (2015) Sustainable groundwater management program draft strategic plan. California Department of Water Resources, Sacramento

California Department of Water Resources (DWR) (2018) Flood-MAR: using flood water for managed aquifer recharge to support sustainable water resources. California Department of Water Resources, Sacramento

California Department of Water Resources (DWR) (2019) Climate change vulnerability assessment. California Department of Water Resources, Sacramento

Christensen, J.H., Kanikicharla, K.K., Marshall, G., and Turner, J. (2013). Climate phenomena and their relevance for future regional climate change

Christian-Smith, J., Moran, T., Persad, G., Smith, G., and Szeptycki, L. (2017). Navigating a flood of information: evaluating and integrating climate science into groundwater planning in California (Union of Concerned Scientists)

Cook BI, Ault TR, Smerdon JE (2015) Unprecedented 21st century drought risk in the American Southwest and Central Plains. Sci Adv 1:e1400082

Das T, Dettinger MD, Cayan DR, Hidalgo HG (2011a) Potential increase in floods in California's Sierra Nevada under future climate projections. Clim Chang 109:71-94

Das T, Pierce DW, Cayan DR, Vano JA, Lettenmaier DP (2011b) The importance of warm season warming to western U.S. streamflow changes. Geophys. Res. Lett. 38

Das T, Maurer EP, Pierce DW, Dettinger MD, Cayan DR (2013) Increases in flood magnitudes in California under warming climates. J Hydrol 501:101-110

Davenport FV, Herrera-Estrada JE, Burke M, Diffenbaugh NS (2020) Flood size increases nonlinearly across the Western United States in response to lower snow-precipitation ratios. Water Resour. Res. 56: e2019WR025571

Diffenbaugh NS, Swain DL, Touma D (2015) Anthropogenic warming has increased drought risk in California. Proc Natl Acad Sci 112:3931-3936

Eum H-I, Vasan A, Simonovic SP (2012) Integrated reservoir management system for flood risk assessment under climate change. Water Resour Manag 26:3785-3802

Forster PM, Maycock AC, McKenna CM, Smith CJ (2020) Latest climate models confirm need for urgent mitigation. Nat Clim Chang 10:7-10

Fyfe JC, Derksen C, Mudryk L, Flato GM, Santer BD, Swart NC, Molotch NP, Zhang X, Wan H, Arora VK et al (2017) Large near-term projected snowpack loss over the western United States. Nat Commun 8:14996

Gershunov A, Shulgina T, Clemesha RES, Guirguis K, Pierce DW, Dettinger MD, Lavers DA, Cayan DR, Polade SD, Kalansky J et al (2019) Precipitation regime change in Western North America: the role of atmospheric rivers. Sci Rep 9:1-11

Ghasemizade M, Asante KO, Petersen C, Kocis T, Dahlke HE, Harter T (2019) An integrated approach toward sustainability via groundwater banking in the southern Central Valley. California Water Resour Res 55: 2742-2759

Gleick PH (1987) The development and testing of a water balance model for climate impact assessment: modeling the Sacramento Basin. Water Resour Res 23:1049-1061

Gonzales KR, Swain DL, Nardi KM, Barnes EA, Diffenbaugh NS (2019) Recent warming of landfalling atmospheric rivers along the west coast of the United States. J Geophys Res Atmospheres 124:6810-6826

Griffin D, Anchukaitis KJ (2014) How unusual is the 2012-2014 California drought? Geophys Res Lett 41: 9017-9023 
Groves DG, Bloom E, Lempert RJ, Fischbach JR, Nevills J, Goshi B (2015) Developing key indicators for adaptive water planning. J Water Resour Plan Manag 141:05014008

Hagemann S, Chen C, Haerter JO, Heinke J, Gerten D, Piani C (2011) Impact of a statistical bias correction on the projected hydrological changes obtained from three GCMs and two hydrology models. J Hydrometeorol 12:556-578

Hausfather Z, Peters GP (2020) Emissions - the 'business as usual' story is misleading. Nature 577:618-620

He M, Anderson M, Schwarz A, Das T, Lynn E, Anderson J, Munévar A, Vasquez J, Arnold W (2019) Potential changes in runoff of California's major water supply watersheds in the 21st century. Water 11:1651

Hidalgo HG, Dettinger MD, Cayan D (2008) Downscaling with constructed analogues: daily precipitation and temperature fields over the United States. California Energy Commission, Sacramento

Huang X, Hall AD, Berg N (2018) Anthropogenic warming impacts on today's Sierra Nevada snowpack and flood risk. Geophys Res Lett 45(12):6215-6222. https://doi.org/10.1029/2018GL077432

Indian Wells Valley Groundwater Authority (IWVGA) (2020) Groundwater sustainability plan for the Indian Wells Valley groundwater basin

Kapnick SB, Delworth TL (2013) Controls of global snow under a changed climate. J Clim 26:5537-5562

Kapnick S, Hall A (2010) Observed climate-snowpack relationships in California and their implications for the future. J Clim 23:3446-3456

Kean JW, Staley DM, Lancaster JT, Rengers FK, Swanson BJ, Coe JA, Hernandez JL, Sigman AJ, Allstadt KE, Lindsay DN (2019) Inundation, flow dynamics, and damage in the 9 January 2018 Montecito debris-flow event, California, USA: opportunities and challenges for post-wildfire risk assessment. Geosphere 15:11401163

Kirtman, B., Power, S.B., Adedoyin, A.J., Boer, G.J., Bojariu, R., Camilloni, I., Doblas-Reyes, F., Fiore, A.M., Kimoto, M., Meehl, G., et al. (2013). Near-term climate change: projections and predictability. In Climate Change 2013 the Physical Science Basis: Working Group I Contribution to the Fifth Assessment Report of the Intergovernmental Panel on Climate Change, pp. 953-1028

Knowles N, Cayan DR (2004) Elevational dependence of projected hydrologic changes in the San Francisco estuary and watershed. Clim Chang 62:319-336

Knowles N, Dettinger MD, Cayan DR (2006) Trends in snowfall versus rainfall in the Western United States. J Clim 19:4545-4559

Knowles N, Cronkite-Ratcliff C, Pierce DW, Cayan DR (2018) Responses of unimpaired flows, storage, and managed flows to scenarios of climate change in the San Francisco Bay-Delta watershed. Water Resour Res 54:7631-7650

Langridge, R., Sepaniak, S., Fencl, A., and Barrientos, E.M. (2018). Management of groundwater and drought under climate change (California Natural Resources Agency)

Lettenmaier DP, Gan TY (1990) Hydrologic sensitivities of the Sacramento-San Joaquin River basin, California, to global warming. Water Resour Res 26:69-86

Lund J, Medellin-Azuara J, Durand J, Stone K (2018) Lessons from California's 2012-2016 drought. J Water Resour Plan Manag 144:04018067

Mao Y, Nijssen B, Lettenmaier DP (2015) Is climate change implicated in the 2013-2014 California drought? A hydrologic perspective. Geophys Res Lett 42:2805-2813

Mearns LO, Gutowski W, Jones R, Leung R, McGinnis S, Nunes A, Qian Y (2009) A regional climate change assessment program for North America. EOS Trans Am Geophys Union 90:311-311

Mote PW, Li S, Lettenmaier DP, Xiao M, Engel R (2018) Dramatic declines in snowpack in the western US. NPJ Clim Atmospheric Sci 1:2

Oakley NS, Cannon F, Munroe R, Lancaster JT, Gomberg D, Ralph FM (2018) Brief communication: meteorological and climatological conditions associated with the 9 January 2018 post-fire debris flows in Montecito and Carpinteria, California. USA Nat Hazards Earth Syst Sci Katlenburg-Lindau 18:3037-3043

Park, D.K., Francois, B., Wi, S., Dufour, A., Rheinheimer, D.E., Bruce, A., Nguyen, K., and Brown, C. (2019). Long term vulnerability assessment platform to support climate-informed decision in water resources planning for Hetch Hetchy Regional Water System. (AGU), p

Pierce D (n.d.) LOCA (localized constructed analogues) validation and verification plots. Retrieved 12 June 2020, from http://loca.ucsd.edu/ pierce/analysis/

Pierce DW, Das T, Cayan DR, Maurer EP, Miller NL, Bao Y, Kanamitsu M, Yoshimura K, Snyder MA, Sloan LC et al (2013a) Probabilistic estimates of future changes in California temperature and precipitation using statistical and dynamical downscaling. Clim Dyn 40:839-856

Pierce DW, Cayan DR, Das T, Maurer EP, Miller NL, Bao Y, Kanamitsu M, Yoshimura K, Snyder MA, Sloan LC et al (2013b) The key role of heavy precipitation events in climate model disagreements of future annual precipitation changes in California. J Clim 26:5879-5896

Pierce DW, Cayan DR, Thrasher BL (2014) Statistical downscaling using localized constructed analogs (LOCA). J Hydrometeorol 15:2558-2585 
Pierce DW, Cayan DR, Maurer EP, Abatzoglou JT, Hegewisch KC (2015) Improved bias correction techniques for hydrological simulations of climate change. J Hydrometeorol 16:2421-2442

Pierce, D.W., Kalansky, J.F., and Cayan, D.R. (2018). Climate, drought, and sea level rise scenarios for the fourth California climate assessment. (California Energy Commission)

Polade SD, Gershunov A, Cayan DR, Dettinger MD, Pierce DW (2017) Precipitation in a warming world: assessing projected hydro-climate changes in California and other Mediterranean climate regions. Sci Rep 7: 10783

Ray P, Wi S, Schwarz A, Correa M, He M, Brown C (2020) Vulnerability and risk: climate change and water supply from California's Central Valley water system. Clim Chang

Schwarz, A., Ray, P., Wi, S., He, M., and Correa, M. (2018). Climate change risk faced by the California Central Valley water resource system (California Natural Resources Agency)

Shibatani, R. (2015). Reservoir re-operation - the sleeping giant in water supply development

Steinschneider S, Ray P, Rahat SH, Kucharski J (2019) A weather-regime-based stochastic weather generator for climate vulnerability assessments of water systems in the western United States. Water Resour Res 55:69236945

Sun F, Hall A, Schwartz M, Walton DB, Berg N (2015) Twenty-first-century snowfall and snowpack changes over the Southern California Mountains. J Clim 29:91-110

Sun F, Berg N, Hall A, Schwartz M, Walton D (2019) Understanding end-of-century snowpack changes over California's Sierra Nevada. Geophys Res Lett 46:933-943

Sustainable Groundwater Management Program (SGMP) (2018) Guidance for climate change data use during groundwater sustainability plan development. California Department of Water Resources, Sacramento

Swain D, Tsiang M, Haugen M, Singh D, Charland A, Rajaratnam B, Diffenbaugh N (2014) The extraordinary California drought of 2013/2014: character, context, and the role of climate change. Bull Am Meteorol Soc 95:S3-S7

Swain DL, Langenbrunner B, Neelin JD, Hall A (2018) Increasing precipitation volatility in twenty-first-century California. Nat Clim Chang 1

Tolley D, Foglia L, Harter T (2019) Sensitivity analysis and calibration of an integrated hydrologic model in an irrigated agricultural basin with a groundwater-dependent ecosystem. Water Resour Res 55:7876-7901

U.S. Army Corps of Engineers (1970) Oroville dam and reservoir-report on reservoir regulation for flood control, appendix IV to master manual of reservoir regulation. Sacramento River Basin, California

van Vuuren DP, Edmonds J, Kainuma M, Riahi K, Thomson A, Hibbard K, Hurtt GC, Kram T, Krey V, Lamarque J-F et al (2011) The representative concentration pathways: an overview. Clim Chang 109:5-31

Vano, J., Hamman, J., Guttman, E., Wood, A., Mizukami, Clark M., Pierce, D.W., Cayan, D.R., Wobus, C., Nowak, K., et al. (2020). Comparing downscaled LOCA and BCSD CMIP5 climate and hydrology projections - release of downscaled LOCA CMIP5 hydrology

Walton D, Sun F, Hall A, Capps SB (2015) A hybrid dynamical-statistical downscaling technique, part I: development and validation of the technique. J Clim 28:4597-4617

Wang S-Y, Hipps L, Gillies RR, Yoon J-H (2014) Probable causes of the abnormal ridge accompanying the 2013-2014 California drought: ENSO precursor and anthropogenic warming footprint. Geophys. Res. Lett. 41:3220-3226

Wang, J., Yin, H., Anderson, J., Reyes, E., Smith, T., and Chung, F. (2018). Mean and extreme climate change impacts on the state water project. California's Fourth Clim. Change Assess. Publ. Number CCCA4-EXT20184

White AB, Moore BJ, Gottas DJ, Neiman PJ (2018) Winter storm conditions leading to excessive runoff above California's Oroville dam during January and February 2017. Bull Am Meteorol Soc 100:55-70

Williams AP, Seager R, Abatzoglou JT, Cook BI, Smerdon JE, Cook ER (2015) Contribution of anthropogenic warming to California drought during 2012-2014. Geophys Res Lett 42:2015GL064924

Wood AW, Maurer EP, Kumar A, Lettenmaier DP (2002) Long-range experimental hydrologic forecasting for the eastern United States. J. Geophys. Res. Atmospheres 107 ACL 6-1-ACL 6-15

Publisher's note Springer Nature remains neutral with regard to jurisdictional claims in published maps and institutional affiliations. 


\section{Affiliations}

\section{Geeta G. Persad ${ }^{1,2} \cdot$ Daniel L. Swain ${ }^{3,4,5} \cdot$ Claire Kouba $^{6} \cdot$ J. Pablo Ortiz-Partida ${ }^{1}$}

Geeta G. Persad

geeta.persad@jsg.utexas.edu

1 Union of Concerned Scientists, Oakland, CA, USA

2 Department of Geological Sciences, University of Texas at Austin, 2305 Speedway Stop C1160, Austin, TX 78712-1692, USA

3 Institute of the Environment and Sustainability, University of California, Los Angeles, Los Angeles, CA, USA

4 Capacity Center for Climate and Weather Extremes, National Center for Atmospheric Research, Boulder, CO, USA

5 The Nature Conservancy of California, San Francisco, CA, USA

6 Department of Land, Air, and Water Resources, University of California, Davis, Davis, CA, USA 